\title{
Photoelectronic Magnetic Microsensor with a Digit Readout
}

\author{
Hsing-Cheng Chang \\ Feng Chia University, Taichung, 40724
}

Taiwan

\section{Introduction}

The magnetic microsensor is a small detective device for sensing magnetic effects and transferring to measurable signals. Magnetic microsensors are important in various application areas that are biomagnetism, geomagnetism, nondestructive testing, automobile, field measurement, identification and communication. Eleven technologies have been described for magnetic field measurements that are search-coil, flux-gate, optically pumped, nuclear precession, SQUID, Hall-effect, magnetoresistive, magnetodiode, magnetotransistor, fiber optical, and magneto-optic (Lenz, 1990). Four-type classification of magnetic microsensors by principle are also summarised that are galvanic, conductimetric, voltaic, and acoustics (Gardner et al., 2001). The trend of sensor development is toward lower cost, small dimension, lower power consumption, and higher performance. A new physics phenomenon using new fabrication technology and improved materials for new applications should be the development trends in magnetic microsensors. Recent progress in applications of FBG sensors has reported (Lee, 2003, Rao, 1999). Different researches on optical magnetic sensors have been addressed by fiber-optic interferometric (Oh et al., 1997, Wang et al., 2008), cantilever bending (Keplinger et al., 2003), Lorentzian force (Okamura, 1990), or magnetic materials (Meng et al., 2001).

Operational principles based on electromagnetic systems, magnetic material properties, stress-induced magnetic interrelationship, fiber gratings, and superconductivity have been widely studied for magnetic detection or measurement (Ciudad et al., 2004; Dimitropoulos et al., 2003; Mapps, 1997; Sedlar et al., 2000; Seo et al., 2001). It must be noticed in magnetic sensors development to immunity the factors of temperature and humidity and optical fiber sensors can be designed to fit the requirement. To develop magnetic microsensor using optical fiber sensing method becomes popular due to the advantages of electromagnetic immunity, electronic isolation, low cost, light weight, small size, and anti-corrosive. Fiber grating sensors has been reviewed based on different grating sensing methods, including Bragg gratings, chirped gratings, long period-based gratings, and intragrating concepts (Kersey et al, 1997). The permalloy-on-membrane type of magnetic actuators with flexural cantilevers and torsion beams are built based on microelectromechanical system (MEMS) technology to satisfy large force and displacement requirements (Khoo \& Liu, 2001, Liu \& $\mathrm{Yi}$, 1990). To develop fiber Bragg grating (FBG) sensors unaffected by temperature perturbations is important for practical applications. A precision optical fiber-based magnetic sensor requires temperature compensation design because of deformation of 
inherent temperature dependence in fiber material. Several temperature compensation techniques in pressure or strain measurements have been established such as bimetal cantilevers, non-uniform or dual head FBGs, double shell cylinders and biomaterial effect (Hsu et al., 2006; Iadicicco et al., 2006; Khoo \& Liu, 2001; Liu \& Yi, 1990; Tian et al., 2005). These techniques guarantee stable measurements independent of temperature perturbation without any additional temperature-isolation or referencing process.

To develop a magnetic microsensor as a microsystem should contain environment sensing mechanism, data processing and storage modules, and automatic calibration and compensation functions. Because of very small magnetostriction rate below the order of $10^{-5}$, the sensing range and reliability of magnetic field strength are limited by coating soft magnetic film on optical fibers directly. Accordingly, microelectromechanical system compatible FBG magnetic sensor can be designed to supply a wide measurement range with solid reliability. A photoelectronic magnetic microsensor with a temperature compensation function and a digital readout has been developed and fabricated as a smart sensing system. The batch of microfabrication technology used to deposit Ni/Cr permalloy flaps that can be driven to push the sensing FBGs by excitation magnetic force to supply capacitive and optical outputs. The finite element method (FEM) for equivalent model simulation was utilized to understand the coupling effect of magnetic and mechanical behaviors. The neodymium-iron-boron (Nd-Fe-B) magnets with residual surface magnetic flux density up to 1.26 Tesla $(\mathrm{T})$ were used as excited power to investigate the influence of external magnetic fields on the density variation of the transmitting light signal. Measurement system and display in real-time mode were setup by connecting the designed microsensors with signal processing circuits and a PC display module.

\section{Operation principle}

\subsection{Sensing theory}

The operational principle of the FBG-based sensors is to monitor the central wavelength shift between input signal and back-reflected signal from the Bragg gratings. The first-order Bragg condition is given by the expression (Morey et al., 1989)

$$
\lambda_{B}=2 n_{e f f} \Lambda
$$

where $\mathrm{n}_{\mathrm{eff}}$ is the effective index of the core and $\Lambda$ is the period of gratings. Bragg wavelength, $\lambda_{\mathrm{B}}$, is the center wavelength of the back-reflected signal from the Bragg gratings.

Most of FBG sensing works have focused on the device design and fabrication for providing quasi-distributed sensing of temperature and strain which can be described as the following equation (Liu et al, 2007, Xu et al., 1993).

$$
\frac{\Delta \lambda}{\lambda_{B}}=\left(1-P_{e}\right) \Delta \varepsilon+\left(\alpha_{f}+\xi_{f}\right) \Delta T=K_{\varepsilon} \varepsilon+K_{T} T
$$

where $\Delta \varepsilon$ is the change of strain; $P_{e}$ is the effective photoelastic coefficient of the fiber glass; $\alpha_{f}$ is the thermal expansion coefficient of fiber; $\xi_{f}$ is the thermal optic coefficient of the fiber; $\Delta T$ is the change of temperature; $K_{\tau}$ is the strain sensitivity; $K_{T}$ is the temperature sensitivity. The strain response arises due to both the sensor elongation induced grating pitch variation and the photoelastic effect induced fiber index change. For measuring magnetic field strength accurately, magnetic force induced strain should be measured effectively with 
processing of temperature compensation. The relative Bragg wavelength shifts in response to axial strain change $\left(\Delta \lambda_{\varepsilon} / \lambda_{B}\right)$ in a packaged FBG sensor can be described as the following equation (Liu et al., 2000).

$$
\frac{\Delta \lambda_{\varepsilon}}{\lambda_{B}}=-\left(1-P_{e}\right) \frac{\Delta P}{E}=K_{P} \Delta P
$$

where $P_{e}$ is the effective photoelastic coefficient; $K_{p}$ is the pressure sensitivity; $E$ is the Young's modulus of the fiber; $\Delta P$ is the change of pressure.

When applying strain and temperature in the fiber, the effective index of the core and the uniform distribution of gratings will be affected to induce the shift in Bragg wavelength. It simply can be expressed using

$$
\frac{\Delta \lambda_{B}}{\lambda_{B}}=C_{1} \Delta \varepsilon+C_{2} \Delta T
$$

where $C_{1}$ and $C_{2}$ present sensing parameters found to be $0.78 \times 10^{-12}$ and $6.67 \times 10^{-6}$ respectively (Kersey et al., 1997). The factors are complicated from strain-optic effect that affected by the parameters of Poisson ratio, core effective index, Pockel's coefficient components, grating length variation, and total fiber grating length. It becomes comprehensible that the variation in wavelength is the sum of the strain and temperature terms. The sensitivities of normalized central wavelength shift to strain and temperature have been studied about $1.17 \times 10^{-3} \mathrm{~nm} / \mu \varepsilon$ and $1 \times 10^{-2} \mathrm{~nm} /{ }^{\circ} \mathrm{C}$ respectively. Therefore, to design a photoelectronic magnetic microsensor with minimizing noise perturbation, the magnetic-actuated strain variation must be detected effectively, but the influence of temperature must be eliminated.

\subsection{Major processes}

Based on planar microfabrication technologies, silicon-based optical-electrical integration structures can be fabricated compatibly. The sensing platform contains a sensor-located Ushaped trench, an etched through sensing window, and an interdigitated magnetic reaction mechanism. Thermal oxidation layers as an etching mask for silicon bulk etching and electrical isolation are grown. Wet chemical etch and sacrificial technologies of bulk and surface micromachining are applied to form location U-shaped trenches and sensing windows and interdigitated actuated mechanism. To achieve magnetic measurement with high permeability, saturation flux, resistivity and low coercivity, interdigitated thin films of $\mathrm{NiFe}\left(\mu_{\mathrm{r}}=2000\right)$ were deposited as magnetic manipulated mechanism by electroplating technology (Flynn, 2007). Each period of sensing grating in FBG devices has $10 \mathrm{~mm}$ long with the separated space of $4 \mathrm{~mm}$. Two different periods of fiber gratings, spectral peaks on $1550.25 \mathrm{~nm}$ and $1553.25 \mathrm{~nm}$, are fabricated in a hydrogen-loaded single-mode fiber (SMF-28) by microlithographic writing technology using a phase-shifted mask and a $248 \mathrm{~nm} \mathrm{KrF}$ excimer laser.

\subsection{System operation}

A flowchart to setup the magnetic flux measurement system with temperature compensation function is shown as Fig. 1. Main program contains three checking processes: 
initial compensation value, effective magnetic force and measurement results. Information of effective magnetic flux measurement will display on a LCD screen or a universal asynchronous receiver transmitter (UART). Temperature compensation configuration on FBG magnetic sensing is shown in Fig. 2. Amplified spontaneous emission (ASE) is used as a lighting source and two FBG optical fibers are used as a sensor and a reference. The reflective spectra of both FBG signals are superposition on the spectrum of a long period grating (LPG) structure. Two photodiodes $\left(\mathrm{PD}_{1}\right.$ and $\left.\mathrm{PD}_{2}\right)$ are used to detect FBG sensing signals. The $\mathrm{PD}_{1}$ measures compound signal from magnetic and temperature effects and $\mathrm{PD}_{2}$ measures temperature effect only. Initial temperature values of $\mathrm{PD}_{1}$ and $\mathrm{PD}_{2}$ and their difference value can be obtained for calculating temperature compensation.

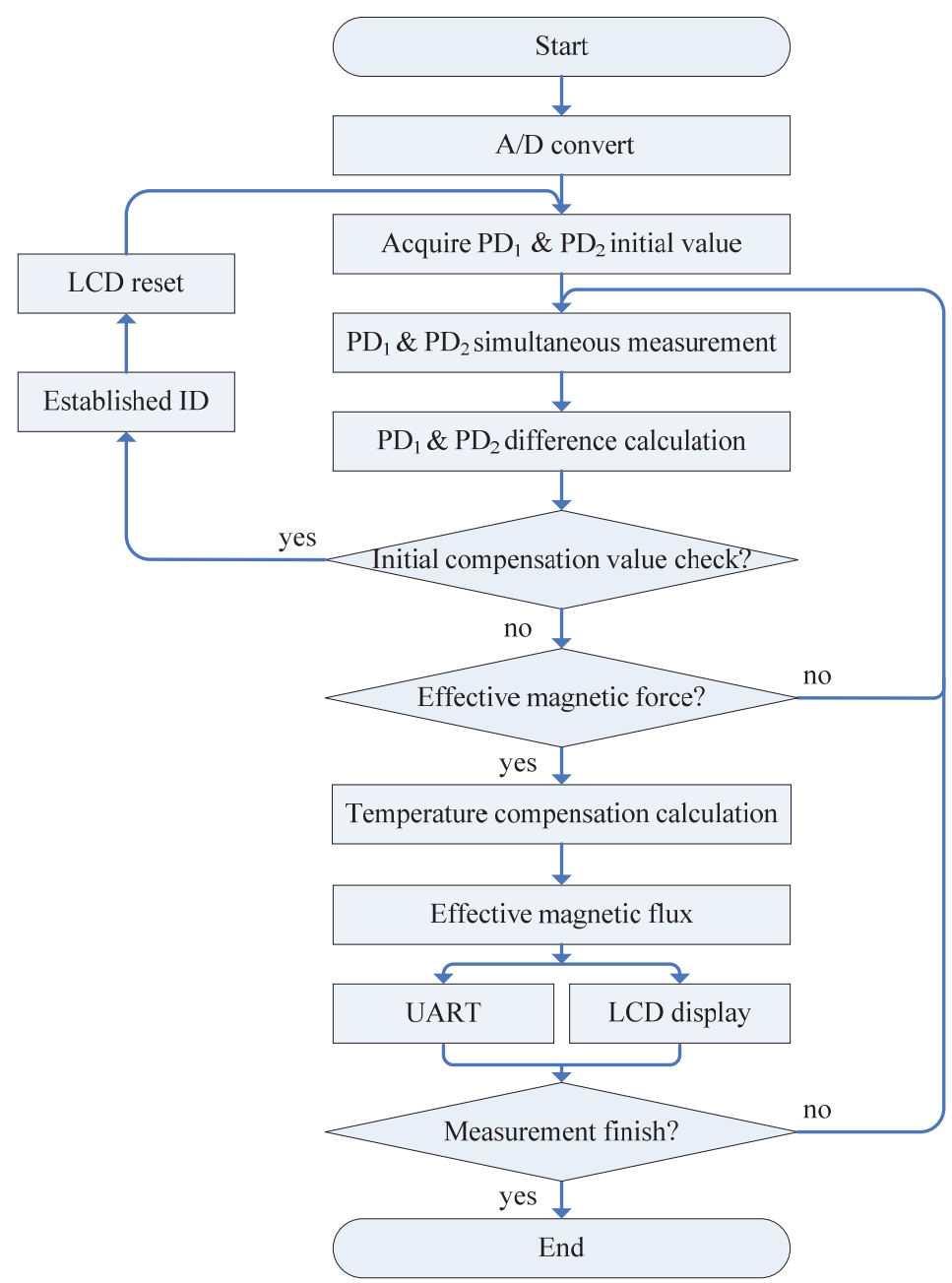

Fig. 1. A flowchart of magnetic flux measurements with temperature compensation 


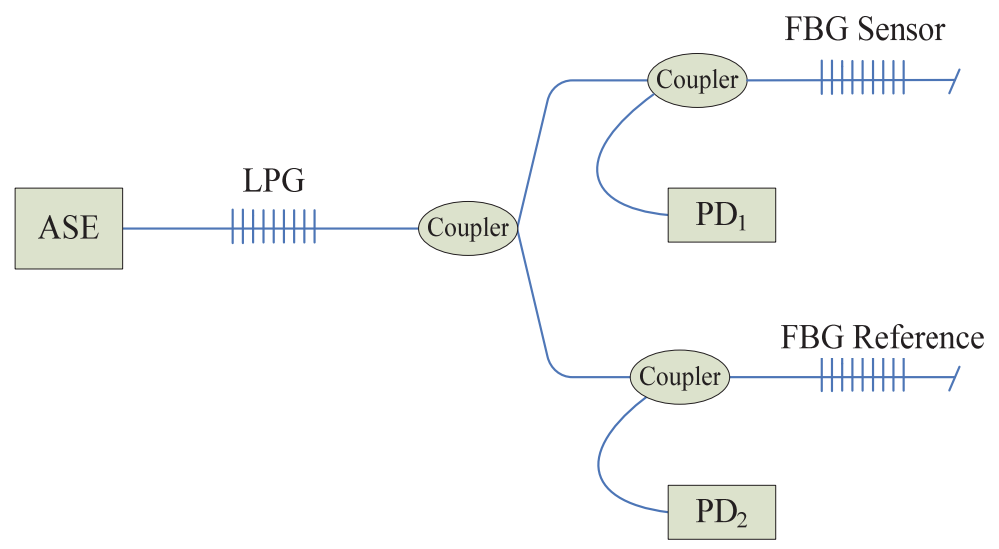

Fig. 2. A typical configuration for FBG temperature compensation

\section{Design and fabrication}

A schematic diagram of the developed photoelectronic magnetic microsensor with the temperature compensation mechanism is shown in Fig. 3. This magnetic microsensor has an optical fiber with two FBGs located on a bulk-etched silicon chip in which one with interdigitated cantilevers is for magnetic flux measurement and the other is for temperature compensation. These FBGs with the grating length of $10 \mathrm{~mm}$ and the separation of $4 \mathrm{~mm}$ are fabricated in a hydrogen-loaded single-mode fiber (SMF-28). When the microsensor is applied to measures magnetic field strength, the cantilevers are attracted and deflected to push fiber a stretch which changes the grating period to induce peak shift of the Bragg wavelength.

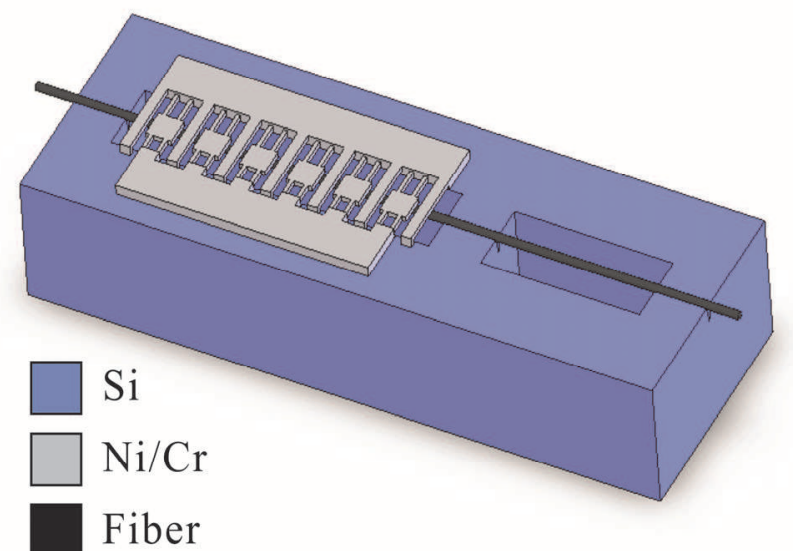

Fig. 3. Schematic diagram of a photoelectronic magnetic microsensor with temperature compensation mechanism 
The major fabrication processes of the developed photoelectronic magnetic microsensor are shown in Fig. 4. (a) Double-sided polished silicon wafers grown a $1 \mu \mathrm{m}$ thermal oxidation layer were used as supporting substrates. (b) Silicon wafer is patterned and etched in both sides to form sensing windows. Anisotropic silicon bulk etching was done in $\mathrm{KOH}$ at $70{ }^{\circ} \mathrm{C}$ to etching a $315 \mu \mathrm{m}$ depth in bottom side and a $113 \mu \mathrm{m}$ depth in top side. (c) Remove the top side $\mathrm{SiO}_{2}$ layer. An adhesion $\mathrm{Cr}$ layer and the $\mathrm{Ni}$ seed layer were evaporated for increasing adhesion. The Ma-P1225 photoresist and a sacrificial photoresist AZ-4620 was spun coated. A two-electrode electroplating system was operated at room temperature. The $\mathrm{Ni}$ is electroplated in aqua solution. A low tensile stress $10 \mu \mathrm{m}$ Ni layer was approached as magnetic actuated cantilevers with maximum permeability and minimum anisotropy field. During the process, wafers were removed from the solution for a short time every minute to desorption of $\mathrm{H}_{2}$ bubbles to increase current. Then AZ-4620 was spun coated and $\mathrm{Ni} / \mathrm{Cr}$ layer was evaporated. (d) The electroplating area is patterned for etching the $\mathrm{Ni} / \mathrm{Cr}$ layer. (e) Sacrificial layer is released and the silicon base is etched out to release cantilevers.

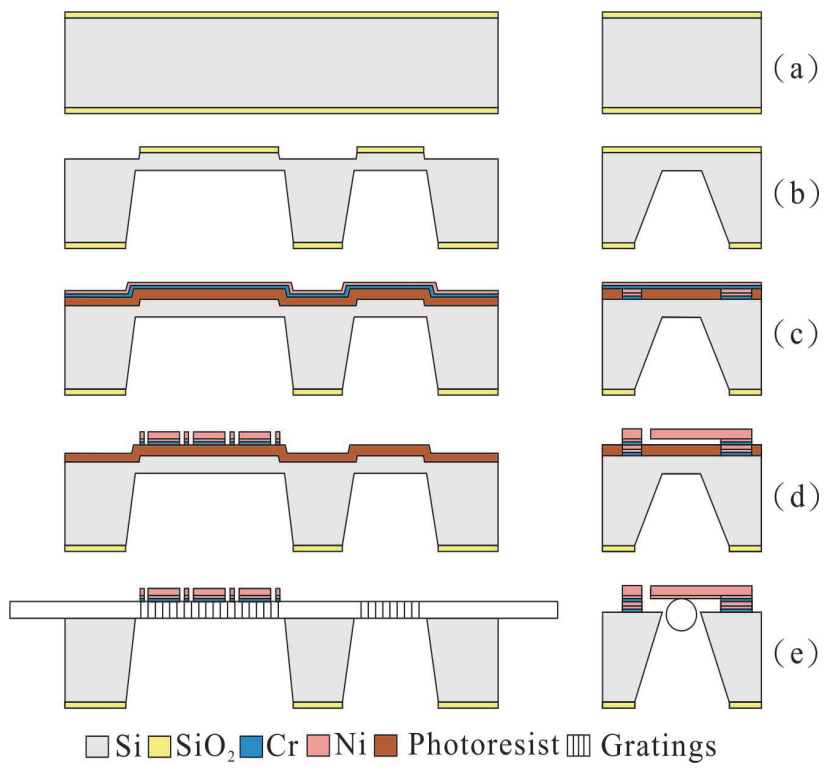

Fig. 4. Major processes of a photoelectronic magnetic microsensor with temperature compensation mechanism, longitudinal cross-sectional structures show in the left and transverse cross-sectional structures show in the right

Another developed photoelectronic magnetic microsensor with EM wave shielded packaging is shown in Fig. 5 (Chang et al., 2007). Fabrication processes of the photoelectronic magnetic microsensor are shown in Fig. 6. (a) A $1 \mu \mathrm{m}$ oxidation layer is grown on silicon substrate. (b) $\mathrm{SiO}_{2}$ layer is UV-lithographic patterned and etched to open silicon etching windows. (c) Silicon bulk is etched anisotropically in $\mathrm{KOH}$ at $60{ }^{\circ} \mathrm{C}$ to define a $30 \mu \mathrm{m}$ thick sensing diaphragm. (d) Polyimide is spun onto the wafer and cured. A Cr layer $(0.02 \mu \mathrm{m})$ and a $\mathrm{Cu}$ seed layer $(0.1 \mu \mathrm{m})$ are deposited for increasing adhesion. A twoelectrode electroplating system is operated at room temperature with a DC current density 
of $15 \mathrm{~mA} / \mathrm{cm}^{2}$. The $\mathrm{Ni} / \mathrm{Fe}$ is electroplated in aqua solution of $\mathrm{NiSO}_{4} / \mathrm{NiCl}_{2} / \mathrm{FeSO}_{4} /$ $\mathrm{H}_{3} \mathrm{BO}_{3}$ /additives. A low tensile stress $5 \mu \mathrm{m} \mathrm{Ni} \mathrm{N}_{0.8} \mathrm{Fe}_{0.2}$ layer was approached as magnetic actuated flaps with maximum permeability and minimum anisotropy field. During the process, the wafers were removed from the solution for a short time every minute to desorption of $\mathrm{H}_{2}$ bubbles to increase current efficiency. Thickness uniformity of permalloy layer is about 1.5 times in the corners because of the edge effect. AFM scanned rms roughness within $20 \mu \mathrm{m} \times 20 \mu \mathrm{m}$ area was $90 \mathrm{~nm}$ for $5 \mu \mathrm{m} \mathrm{Ni} \mathrm{Ni}_{0.8} \mathrm{Fe}_{0.2}$ layer. The supporting silicon layer is etched out to release the membranes. From (e) to (f), second silicon wafer is patterned and etched anisotropically to define the measurement tunnel and a U-shaped trench for locating sensing fibers. The NiFe layer is electroplated for reducing interference. (g) The wafers are bonded and packaged with an Al-deposited cover as the fixed electrode of the capacitor. A soft silicone rubber layer is spun coated around measurement windows for increasing stability and safety. The interdigitated cantilevers as the actuated mechanism in developed photoelectronic magnetic microsensor are simulated and analyzed by the finite element modeling using the ANSYS ${ }^{\circledR}$ software. A typical FEM simulation with interdigitated cantilever size, $1000 \times 1000 \times 10 \mu^{3}$, deflected by external magnetic force is shown in Fig. 7. Different experimental diameters of the fibers have been achieved for optimal sensitivity using a selective wet etching technique with the solutions of trichloroethylene, xylene and hydrofluoric acid driven by an automatic instrumentation. Based on original $125 \mu \mathrm{m}$ diameter of the single-mode fiber, related diameters of $65,80,95$ and $110 \mu \mathrm{m}$ in the parts of fiber gratings obtained. The simulation results that show the magnetic flux induced bending displacements related to different fiber diameters are shown in Fig. 8. Results show that the thinner the fiber diameter is, the higher the sensitivity obtains. A comparison of refraction spectra before and after side-polished FBG with iron coated films was studied (Tien et al., 2006).
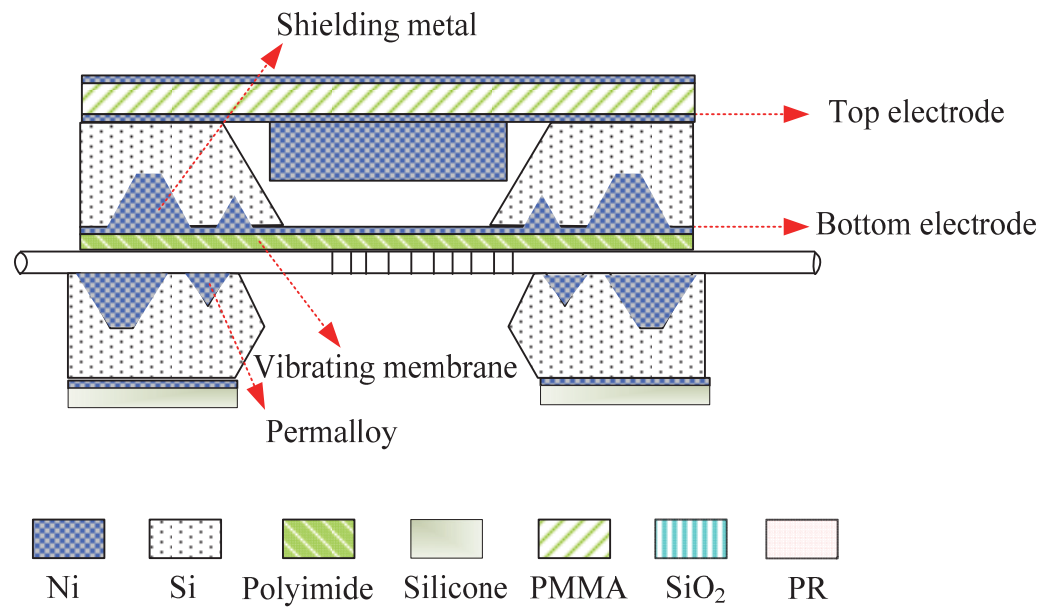

Fig. 5. Schematic diagram of a photoelectronic magnetic microsensor with EM waveshielded packaging 
(a)

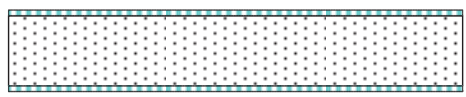

(b)

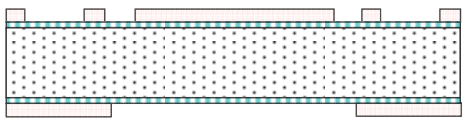

(c)

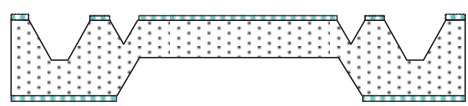

(d)

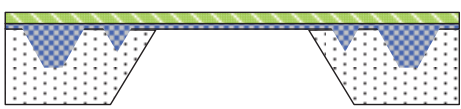

(e)

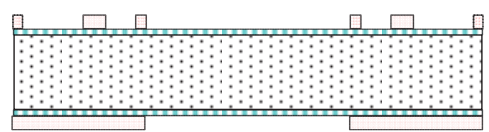

(f)
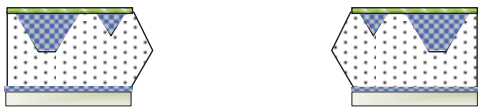

(g)

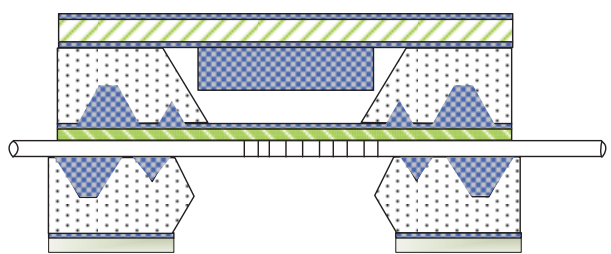

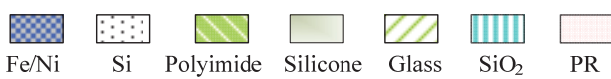

Fig. 6. Fabrication processes of the photoelectronic magnetic microsensor with EM waveshielded packaging

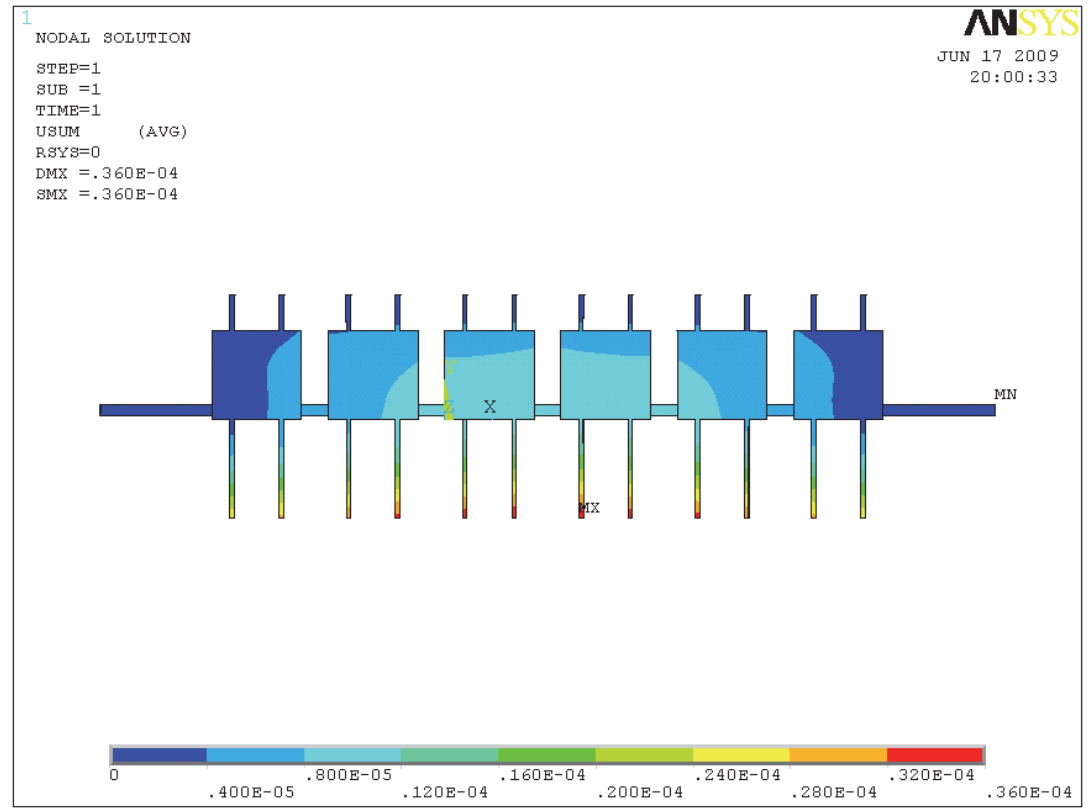

Fig. 7. FEM simulation using ANSYS to estimate cantilever bended conditions by magnetic force 


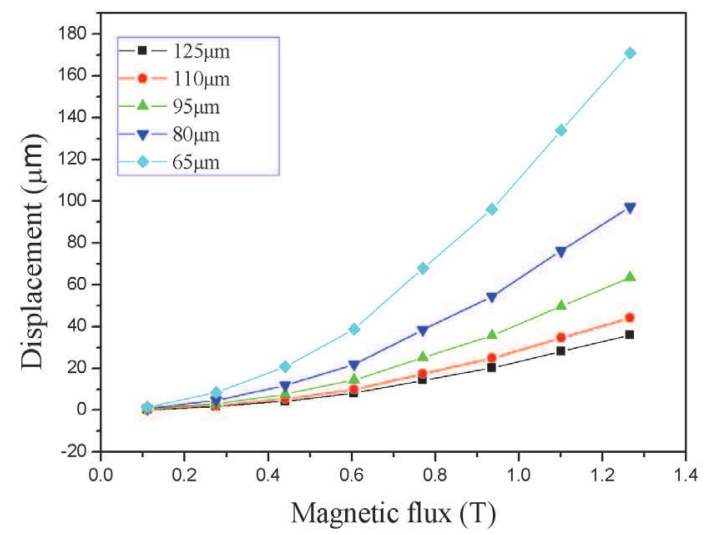

Fig. 8. Magnetic flux induced displacement related to different diameters of fibers

\section{Measurement and analysis}

The schematic cross-sectional view of the microsensor with interference reducing patterns connecting with measurement blocks is shown in Fig. 9. When actuated by the magnetic field, the membrane deflects to push fiber grating stretch that induce peak shift of the Bragg wavelength. The stretched fiber induces Ni-Fe film deformation actuated by external magnetic force that is the cause of fiber stretch to change the effective refraction index. The peak shift amount of Bragg wavelength is proportional to radial magnetic force measured using an optical spectrum analyzer with $0.01 \mathrm{~nm}$ resolution. Developed sensing structure of the microsensor includes a $300 \mathrm{~nm}$ Fe-film coated on FBG fiber and a parallel-plate capacitor both are deformed by a permalloy embedded polyimide membrane. Another measurement block diagram in the schematic cross-sectional view of the developed photoelectronic magnetic microsensor with temperature compensation is shown in Fig. 10. The sensing mechanism is the FBGs actuated by the covered cantilevers that a ferromagnetic material is topped on the surface. The cantilevers are attracted and bended to deform the optical gratings by magnetic flux density from external Nd-Fe-B magnets. The peak shift of the Bragg wavelength is produced from the major variations of the grating length and the fiber core effective refraction index. A precision LCR meter (Agilent E4980A) is used to measure magnetic induced capacitance variation because of the parallel interdigitated cantilever bends. The measured electrical response is in the range of 1.22 to $38.25 \mathrm{pF}$ that is applied as a calibrating reference for comparing optical response excited by external magnetic flux. The signal of position-dependent capacitances is very weak that can be processed by designing capacitance-to-frequency transferred circuits to amplify magnetic response signal. Instruments used in the optical-magnetic measurements are very expensive commercial products. Therefore, to develop a precision, low cost, and portable measurement system is desired. The angular-orientation interference measurement of the permalloy surrounded packaging is shown in Fig. 11 to analyze environmental magnetic noise effect. The peak shift amount of Bragg wavelength is proportional to vertical radial magnetic force measured using an optical spectrum analyzer with $0.01 \mathrm{~nm}$ resolution. Original wave patterns of the 
reflection spectrum were calibrated as shown in Fig. 12. Experimental results show that noise can be reduced effectively when the photoelectronic magnetic microsensor with EM shielded packaging. Comparing with the responded pattern of temperature compensation, the central peak of wavelength of the sensing grating driven by bending cantilevers has shifted into the right side of long wavelength direction. The static wave patterns of the magnetic microsensor with an $80 \%$ peak reflectivity and a $0.150 \mathrm{~nm}$ bandwidth, which wavelength peaks are $1550.24 \mathrm{~nm}$ and $1553.25 \mathrm{~nm}$ at $20^{\circ} \mathrm{C}$.

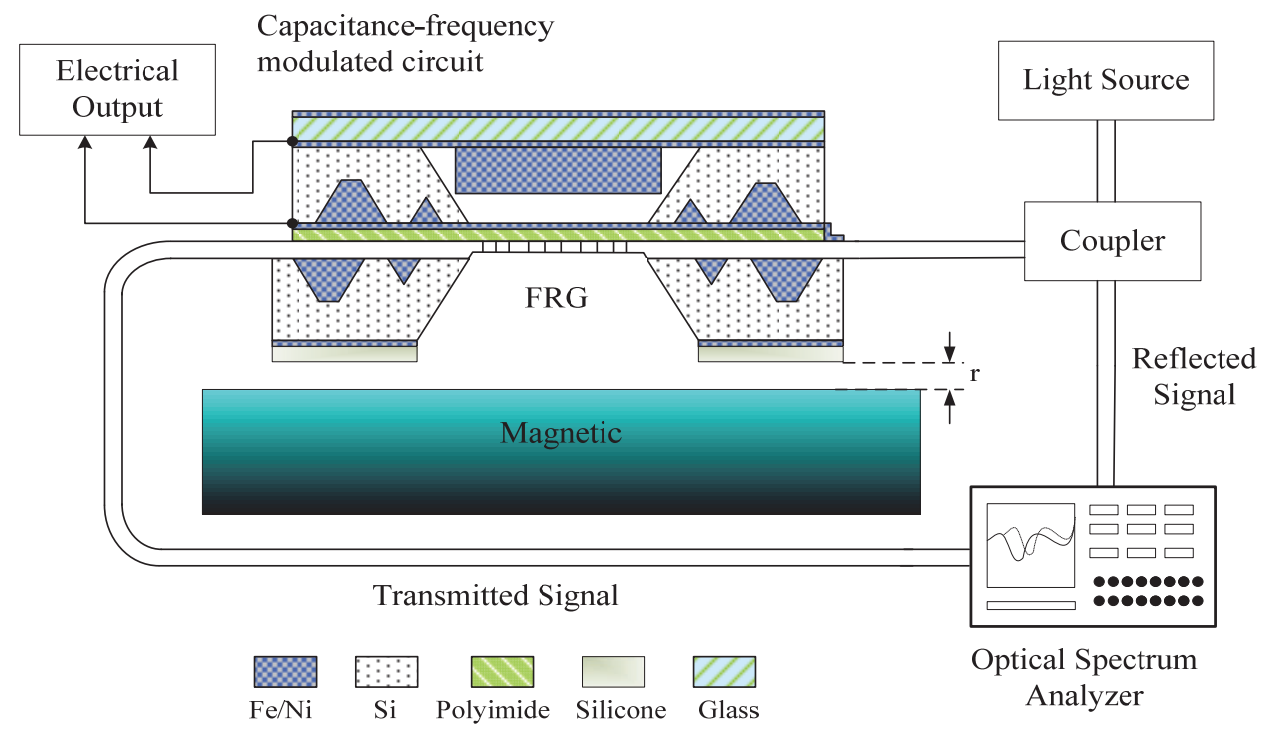

Fig. 9. Schematic diagram of the photoelectronic magnetic microsensor with measuring setup blocks

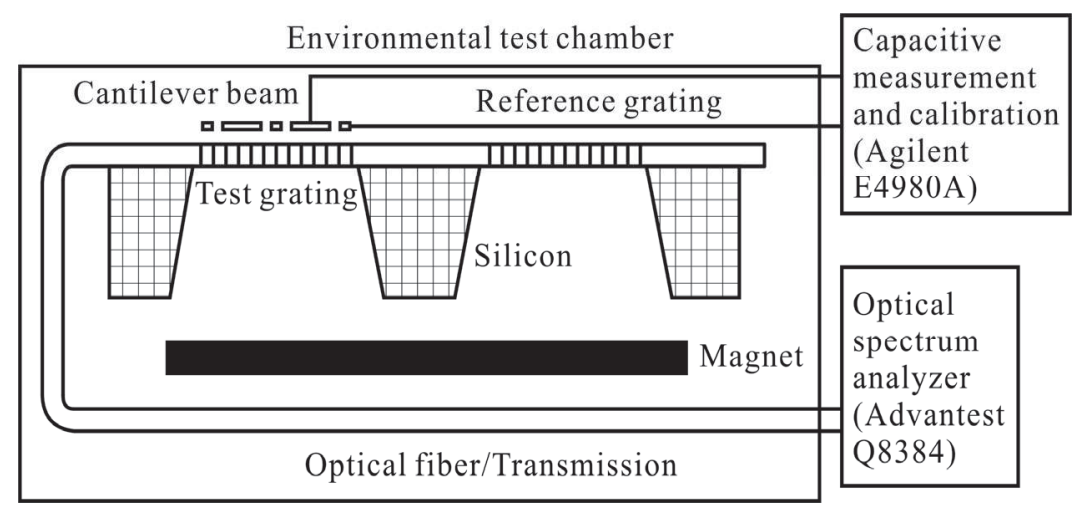

Fig. 10. Experimental setup of the photoelectronic magnetic microsensor with temperature compensation 


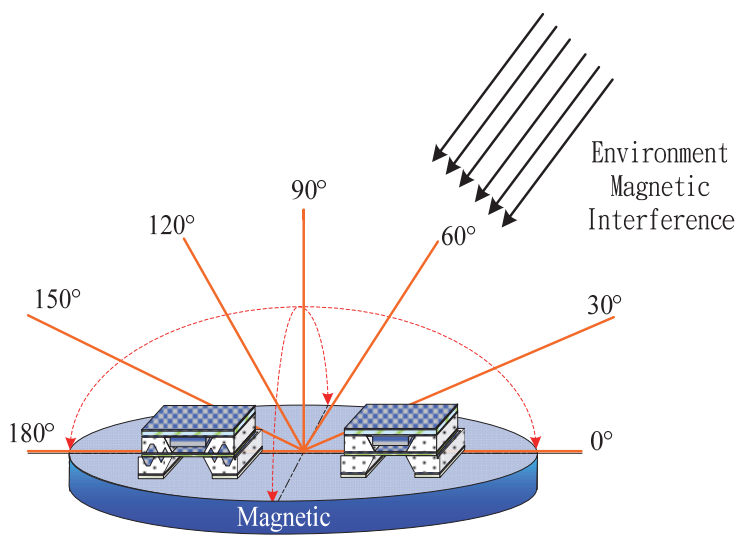

Fig. 11. Schematic of angular-orientation interference measurements for the packaged magnetic microsensors with and without permalloy surrounded

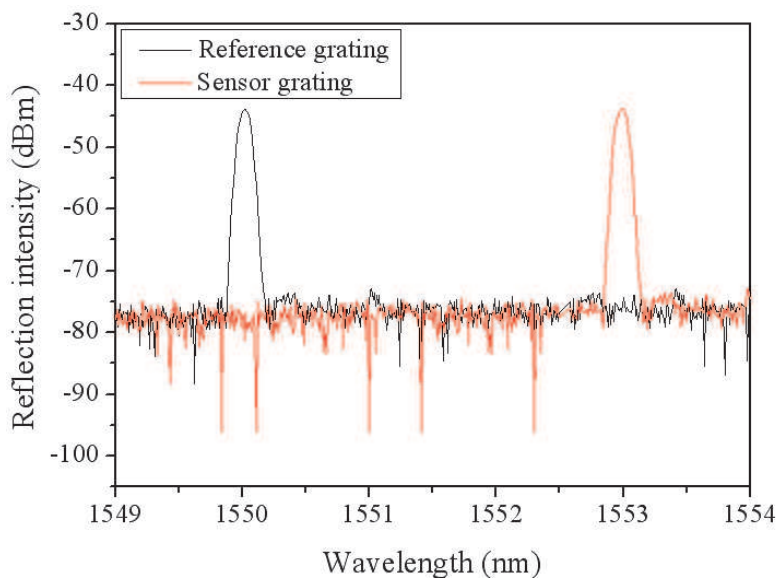

Fig. 12. Static reflection wave patterns at $20^{\circ} \mathrm{C}$, central peak wavelength are $1550.24 \mathrm{~nm}$ and $1553.25 \mathrm{~nm}$ for compensation gratings and sensor's gratings respectively

Temperature effects and related compensation results of the developed FBG microsensors without any magnetic loading reaction are analyzed and shown in Fig. 13. The temperature sensitivities of FBG sensors are $1.175 \times 10^{-2}$ and $1.153 \times 10^{-2} \mathrm{~nm} / \mathrm{deg}$ for sensor and reference structures, respectively. There is temperature induced error less than $1 \%$ that is much smaller than magnetic flux sensing responses induced variation, therefore a null deviation of temperature compensation can be obtained by calibrating. The residual magnetic strength of Nd-Fe-B magnets up to $1.26 \mathrm{~T}$ was used to achieve temperature-independent magnetic measurements by evaluating the Bragg wavelength shift with sensitivity about $2.145 \mathrm{~T} / \mathrm{nm}$. A linear measurement approach in the range of 0 to $450 \mathrm{mT}$ with the average error less than $0.1 \%$ has been demonstrated that can be applied for precision magnetic measurement. The magnetic attractive force from a calibrated magnet is inverse proportional to the square of the distance between developed microsensor and the magnet. 


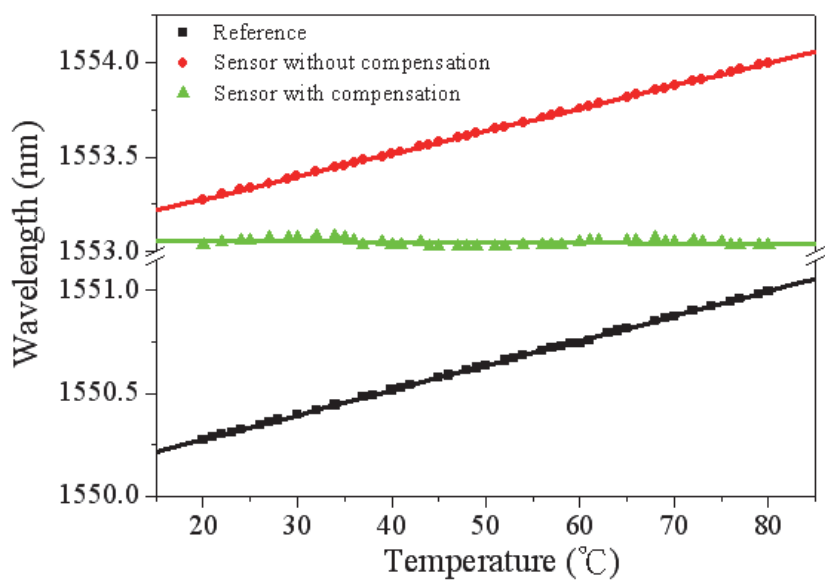

Fig. 13. Temperature induced responses and related compensation results of the developed FBG microsensor without any magnetic effect

The response curves in Fig. 14 present the measured center Bragg wavelength shifts and the net variations as the function of magnetic flux density. Responses without temperature compensation have different curves in separation to show magnetic response with temperature noise that have less sensitivity and high deviation at high temperature region. The curve slopes as magnetic sensitivity are smaller than the theoretical value. This is due to uncertainties of the FBG fiber properties in Young's modulus, Poisson's ration, and stress-optic coefficient with a high resistance in the optical-mechanical coupling reaction. The temperature independent sensitivity of the microsensors by evaluating the Bragg wavelength shift is about $2.238 \mathrm{~T} / \mathrm{nm}$, and all curves of the magnetic responses with temperature compensation are closely overlap with very small deviation measured in variable temperature environment.

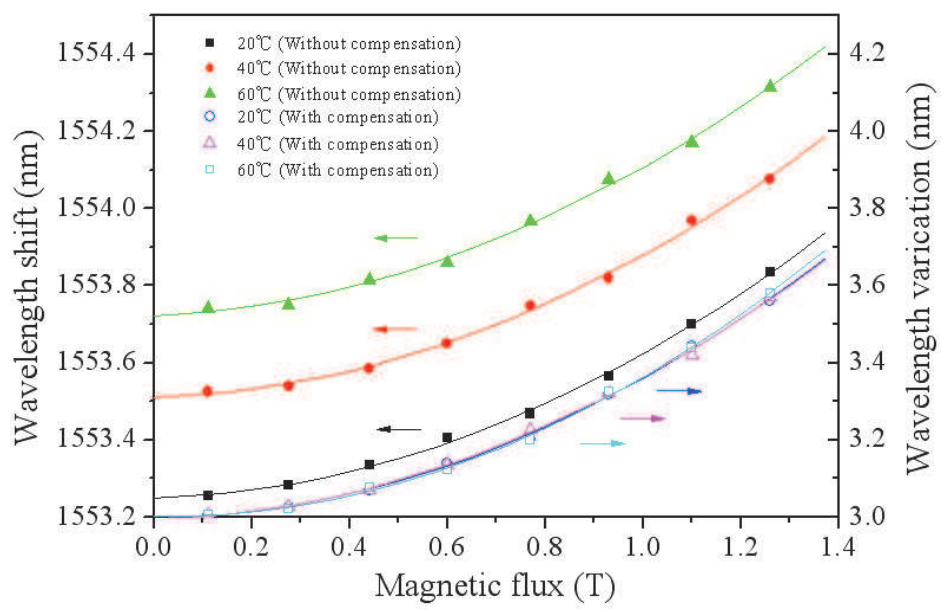

Fig. 14. Experimental results show reflected central wavelength shifts and the equivalent sensing variation induced by different magnetic fluxes of magnets 
Based on simple FBG signal measurement technology using expensive instrumentation (Huang et al., 2007, Kersey et al, 1997), a reliable low cost and portable measurement system is designed in the research for measuring photoelectronic magnetic field or even for universal optical sensing applications shown as Fig. 15. The photodiodes are used as the receivers to detect FBG microsensor signals and a non-biased resistance is optimal matched for better sensitivity. The signal of photocurrent is converted to sinusoidal voltage via selected resistance as input signal for amplifier, filter, and peak detection circuits. Analog voltage signals converted into digital signals by an A/D converter that is sent to a microprocessor to perform the functions of data acquisition, calculation, storage and display control in real-time mode. Measured and analyzed information is shown on LCD display or a computer human-machine interface (HMI) through a RS232 serial transmission.

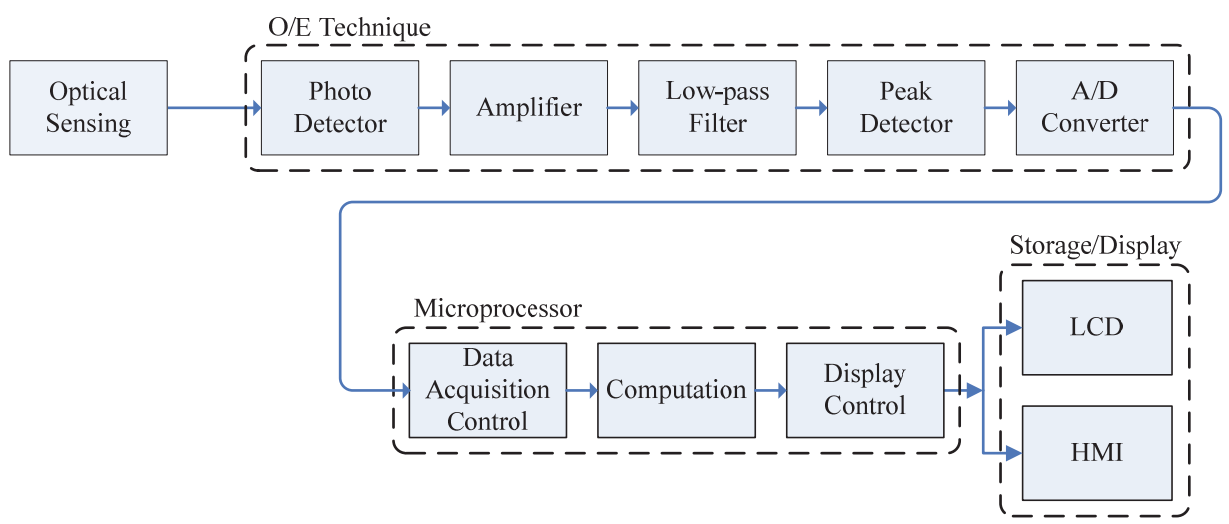

Fig. 15. The block diagram of a measurement system for developed photoelectronic sensors

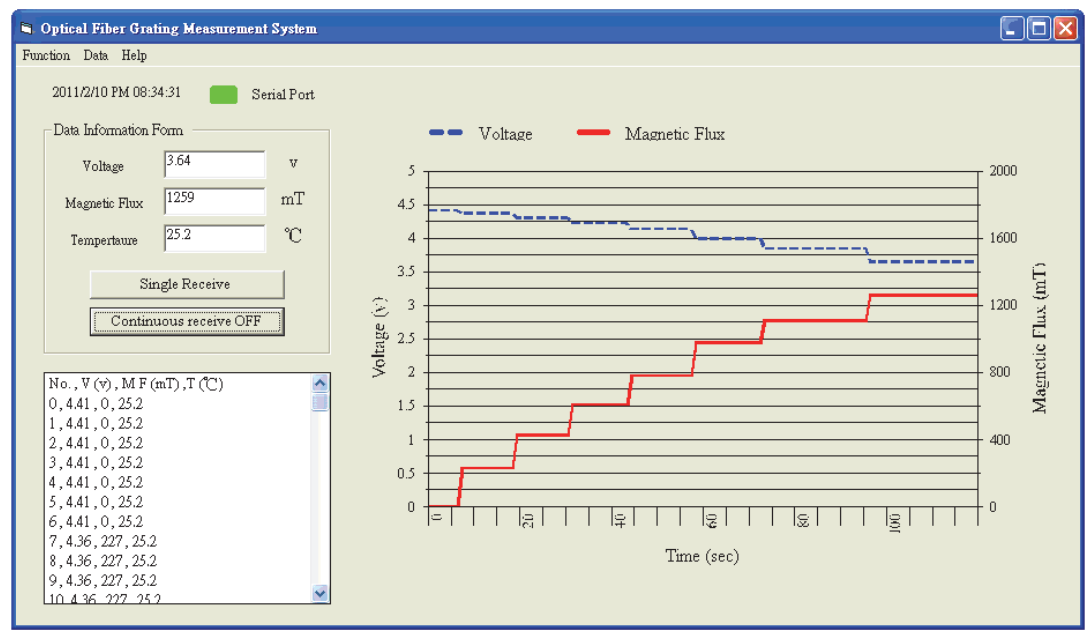

Fig. 16. A typical digital readout of human-machine interface for the photoelectronic magnetic microsensor 
Fig. 16 shows a typical HMI used in a photoelectronic magnetic microsensor measurement. Dynamic measurement and analyzed information, data acquisition and storage do show on the screen in real-time mode.

\section{Conclusion}

The novel FBG-based magnetic microsensors with temperature compensation and EM shielded packaging have been fabricated and tested. Computer simulation has been successfully applied to optimize design parameters of microsensing structures. Electroplated permalloy cantilevers interact with magnets to provide bending force for expanding fiber gratings. Experiments have demonstrated the external magnetic flux on the order of $1.26 \mathrm{~T}$ can be provided $350 \mu \mathrm{m}$ displacements of the cantilevers and $0.59 \mathrm{~nm}$ wavelength differences between the dual FBG. The test and reference gratings have same temperature sensitivity of $0.012 \pm 0.001 \mathrm{~nm} /{ }^{\circ} \mathrm{C}$ to cancel temperature-induced deviation. The magnetic sensitivity of $2.145 \mathrm{~T} / \mathrm{nm}$ has been achieved using Nd-Fe-B magnets with residual magnetic strength up to $1.26 \mathrm{~T}$. The signal processing circuits and the display HMI for digital readout in real-time mode are designed for static and dynamic magnetic flux measurements. Developed reliable low cost and portable measurement system can be applied to universal strain-induced photoelectrical sensing mechanism.

\section{Acknowledgment}

The National Science Council of Republic of China financially supporting is appreciated. The author would like to thank Dr. W. H Liu of Electrical Engineering Department for his help in FBG fabrication. Graduate students of the MEMS and Automation Lab. of Automatic Control Engineering Department provided invaluable technical assistance.

\section{References}

Ambrosino C. Capoluongo P. Campopiano S. Cutolo A. Giordano M. Devino D. Visone C. \& Cusano A. (2007). Fiber Bragg grating and magnetic shape memory alloy: novel high-sensitivity magnetic sensor, IEEE Sensors Journal, Vol. 7, No. 2, (February, 2007), pp. (228-229), ISSN1530437x

Chang H. C. Hwang C. C. Liu C. C. \& Tseng C. L. (2007), An opto-mechatronic magnetic field microsensor, Physica Status Solidi (a), Vol. 204, No. 12, (December, 2007), pp. (4079-4082), ISSN39134208

Ciudad D. Aroca C. Sánchez M. C. Lopez E. \& Sánchez P. (2004), Modeling and fabrication of a MEMS magnetostatic magnetic sensor, Sensors and Actuators A, Vol. 115, No. 23, (September, 2004), pp. (408-416), ISSN09244247

Dimitropoulos P. D. Avaritsiotis J. N. \& Hristoforou E. (2003), A novel micro-fluxgate sensor based on the AMR effect of ferromagnetic film-resistors, Sensors and Actuators A, Vol. 107,No. 3, (November, 2003), pp. (238-247), ISSN09244247

Flynn D. Toon A. Allen L. Dhariwal R. \& Desmulliez M. P. Y. (2007), Characterization of core materials for microscale magnetic components operating in the megahertz frequency range, IEEE Transactions on Magnetics, Vol. 43, No. 7, (July, 2007), pp. (3171-3180), ISSN00189464 
Gardner J. W. Varadan V. K. \& Awadelkarim O. O. (2001), Microsensors, MEMS, and Smart Devices, John Wiley \& Sons, Inc. ISBN047186109x, New York, USA

Hsu Y. S. Wang L. Liu W. F. \& Chiang Y. J. (2006), Temperature Compensation of Optical Fiber Bragg Grating Pressure Sensor, IEEE Photonics Technology Letters, Vol. 18, No. 7, (April, 2006), pp. (874-876), ISSN10411135

Huang X. F. Sheng D. R. Cen K. F. \& Zhou H. (2007) Low-cost relative humidity sensor based on thermoplastic polyimide-coated fiber Bragg grating, Sensors and Actuators $B$, Vol. 127, No. 2, (November, 2007), pp. (518-524), ISSN09254005

Iadicicco A. Campopiano S. Cutolo A. Giordano M. \& Cusano A. (2006), Self temperature referenced refractive index sensor by non-uniform thinned fiber Bragg gratings, Sensors and Actuators B, Vol. 120, No. 1, (December, 2006), pp. (231-237), ISSN 09254005

Keplinger F. Kvasnica S. Hauser H. \& Grossinger R. (2003), Optical readouts of cantilever bending designed for high magnetic field application, IEEE Transactions on Magnetics, Vol. 39, No. 56, (September, 2003), pp. (3304-3306), ISSN00189464

Khoo M. \& Liu C. (2001), Micro Magnetic Silicone Elastomer Membrane Actuator, Sensors and Actuators A, Vol. 89, No. 3, (April, 2001), pp. (259-266), ISSN09244247

Kersey A. D. Davis M. A. Patrick H. J. LeBlanc M. Koo K. P. Askins C. G. Putnam M. A. \& Friebele E. J. (1997), Fiber Grating Sensors, Journal of Lightwave Technology, Vol. 15, No. 8, (August, 1997), pp. (1442-1463), ISSN07338724

Lee B. (2003), Review of the present status of optical fiber sensors, Optical Fiber Technology, Vol. 9, No. 2, (April, 2003), pp. (57-59), ISSN10685200

Lenz J. E. (1990). A Review of Magnetic Sensors, Proceedings IEEE of Magnetics, Vol. 78, No. 6, (June 1990), PP. (973-989), ISSN00189219

Liu C. \& Yi Y. W. (1990), Micromachined Magnetic Actuators Using Electroplated Permalloy, IEEE Transactions on Magnetics, Vol. 35, No.3, (1990), pp. (1976-1985), ISSN 00189464

Liu Y. Guo Z. Zhang Y. Chiang K. S. \& Dong X. (2000), Simultaneous pressure and temperature measurement with polymer-coated fiber Bragg gratings, Electronic Letter, Vol. 36, (March, 2000), pp. (564-566), ISSN00135194

Mapps D. J. (1997), Magnetoresistive sensors, Sensors and Actuators A, Vol. 59, No. 1-3, (April, 1997), pp. (9-19), ISSN09244247

Meng Z. Hu Y. Chen Z. \& Long X. (2001), Miniature optical fiber sensor for alternating magnetic fields based on In-BiCa vanadium iron garnet crystal, IEEE Transactions on Magnetics, Vol. 37, No.5, (September, 2001), pp. (3807-3809), ISSN00189464

Morey W. W. Meltz G. \& Glenn W. H. (1989), Fiber Bragg grating sensors, Proc. SPIE Fiber Optic \& Laser Sensors VII, Vol. 1169, (January, 1989), pp. (98-107), ISBN 9780819402059

Oh K. D. Ranade J. Arya V. Wang A. \& Claus R. O. (1997), Optical fiber Fabry-Perot interferometric sensor for magnetic field measurement, IEEE Photonics Technology Letters, Vol. 9, No. 6, (June, 1997), pp. (797-799), ISSN10411135

Rao Y. J. (1999), Recent progress in applications of in-fiber Bragg grating sensors, Optical Lasers Engineering, Vol. 31, No. 4, (April, 1999), pp. (297-324), ISSN01438166

Sedlar M. Matejec V. \& Paulicka I. (2000), Optical fibre magnetic field sensors using ceramic magnetostrictive jackets, Sensors and Actuators A, Vol. 84, No. 3, (September, 2000), pp. (297-302), ISSN09244247 
Seo Y. H. Han K. H. \& Cho Y. H. (2001), New plasma Hall effect magnetic Sensors: macrosensors versus microsensors, Sensors and Actuators A, Vol. 92, No. 1-3, (August, 2001), pp. (123-131), ISSN09244247

Tian K. Liu Y. \& Wang O. (2005), Temperature-independent fiber Bragg grating strain sensor using bimetal cantilever, Optical Fiber Technology, Vol. 11, No. 4, (October, 2005), pp. (370-377), ISSN10685200

Tien C. L. Hwang C. C. Chen H. W. Liu W. F. \& Lin S. W. (2006), Magnetic sensor based on side-polished fiber Bragg grating coated with iron film, IEEE Transactions on Magnetics, Vol. 42, No. 10, (October, 2006), pp. (3285-3287), ISSN00189464

Wang X. Chen S. Du Z. Shi C. \& Chen J. (2008), Experimental study of some key issues on fiber-optic interferometric sensors detecting weak magnetic field, IEEE Sensors Journal, Vol. 8, No. 7, (July, 2008), pp. (1173-1179), ISSN1530437x

Xu M. G. Reekie L. Chow Y. T. \& Darkin J. P. (1993), Optical in-fiber grating high pressure sensor, Electronic Letter, Vol. 29, (February, 1993), pp. (398-399), ISSN00135194 


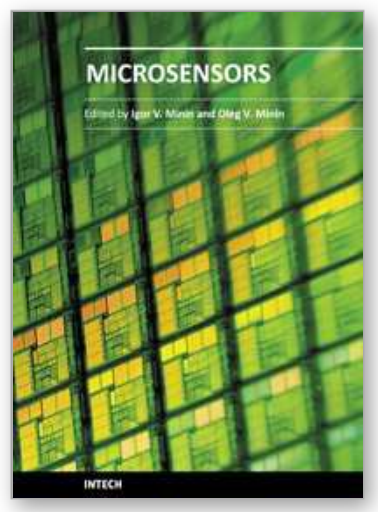

\author{
Microsensors \\ Edited by Prof. Igor Minin
}

ISBN 978-953-307-170-1

Hard cover, 294 pages

Publisher InTech

Published online 09, June, 2011

Published in print edition June, 2011

This book is planned to publish with an objective to provide a state-of-art reference book in the area of microsensors for engineers, scientists, applied physicists and post-graduate students. Also the aim of the book is the continuous and timely dissemination of new and innovative research and developments in microsensors. This reference book is a collection of 13 chapters characterized in 4 parts: magnetic sensors, chemical, optical microsensors and applications. This book provides an overview of resonant magnetic field microsensors based on MEMS, optical microsensors, the main design and fabrication problems of miniature sensors of physical, chemical and biochemical microsensors, chemical microsensors with ordered nanostructures, surfaceenhanced Raman scattering microsensors based on hybrid nanoparticles, etc. Several interesting applications area are also discusses in the book like MEMS gyroscopes for consumer and industrial applications, microsensors for non invasive imaging in experimental biology, a heat flux microsensor for direct measurements in plasma surface interactions and so on.

\title{
How to reference
}

In order to correctly reference this scholarly work, feel free to copy and paste the following:

Hsing-Cheng Chang (2011). Photoelectronic Magnetic Microsensors with a Digit Readout, Microsensors, Prof. Igor Minin (Ed.), ISBN: 978-953-307-170-1, InTech, Available from:

http://www.intechopen.com/books/microsensors/photoelectronic-magnetic-microsensors-with-a-digit-readout

\section{INTECH}

open science | open minds

\section{InTech Europe}

University Campus STeP Ri

Slavka Krautzeka 83/A

51000 Rijeka, Croatia

Phone: +385 (51) 770447

Fax: +385 (51) 686166

www.intechopen.com

\section{InTech China}

Unit 405, Office Block, Hotel Equatorial Shanghai

No.65, Yan An Road (West), Shanghai, 200040, China

中国上海市延安西路65号上海国际贵都大饭店办公楼 405 单元

Phone: +86-21-62489820

Fax: $+86-21-62489821$ 
(C) 2011 The Author(s). Licensee IntechOpen. This chapter is distributed under the terms of the Creative Commons Attribution-NonCommercialShareAlike-3.0 License, which permits use, distribution and reproduction for non-commercial purposes, provided the original is properly cited and derivative works building on this content are distributed under the same license. 